CUADERNOS DE ESTUDIOS GALLEGOS, LXV Núm. 131 (enero-diciembre 2018), págs. 283-305

ISSN: $0210-847 \mathrm{X}$

https://doi.org/10.3989/ceg.2018.131.10

\title{
EL ESCLAVO NEGRO DE LA CIUDAD DE LUGO
}

\author{
Francisco Xabier LouZao Martínez \\ Universidade da Coruña \\ ORCID iD: http://orcid.org/0000-0002-6703-0461
}

Copyright: (C) 2018 CSIC. La edición electrónica de esta revista se distribuye bajo los términos de una licencia de uso y distribución Creative Commons Reconocimiento 4.0 Internacional (CC BY 4.0).

Cómo citar/Citation: Francisco Xabier Louzao Martínez, "El esclavo negro de la ciudad de Lugo", Cuadernos de Estudios Gallegos, 65, núm. 131 (2018), págs. 283-305, https://doi.org/ 10.3989/ceg.2018.131.10 


\title{
EL ESCLAVO NEGRO DE LA CIUDAD DE LUGO
}

\section{RESUMEN}

Las actas del consistorio lucense nos permiten conocer la existencia de un esclavo negro que fue comprado por la ciudad en los primeros años del siglo XVIII. Se buscaba con ello, sin duda, estar a la altura de otras más reconocidas, a las que se trataba de emular a través de nuevos símbolos de prestigio, como daba la posesión de un esclavo. No es algo muy habitual en el mundo gallego y menos todavía en la provincia lucense. El hecho de encontrarse bien documentada su corta existencia en la ciudad lo hace acreedor de un especial interés.

Palabras clave: Clarín, consistorio, esclavitud, esclavos, negro, negrero.

\section{O ESCRAVO NEGRO DA CIDADE DE LUGO}

Resumo

As actas do consistorio lugués permítennos coñecer a existencia dun escravo negro que foi mercado pola cidade nos primeiros anos do século XVIII. Buscábase, sen dúbida, estar á altura doutras máis sobranceiras, ás que se trataba de imitar a través de novos símbolos de prestixio, como daba a posesión dun escravo. Non é algo moi habitual no mundo galego e menos aínda na provincia lucense. O feito de se atopar ben documentada a súa curta existencia na cidade faino acredor dun especial interese.

Palabras Clave: Clarín, consistorio, escravitude, escravos, negro, negreiro.

\section{THE BLACK SLAVE OF THE CITY OF LUGO}

\begin{abstract}
The proceedings of the Lugo city council allow us to know of the existence of a black slave who was bought by the city in the early 18 th century. The aim was to achieve the same status as more renowned cities, as the possession of a slave was a symbol of prestige. It is not common in the Galician world, and even less in the province of Lugo. The fact that his short life in the city is well-documented makes him worthy of special interest.

Key words: Clarín, City Council, Slavery, Slave, Black, Slaver.
\end{abstract}


a esclavitud en el mundo hispánico ha sido objeto de atención por los estudiosos especialmente en la época medieval y los comienzos de la Edad Moderna, y de manera muy concreta en regiones y ciudades de la península en las que este fenómeno adquirió especial protagonismo, a pesar de ser propia de épocas bien anteriores, como la antigüedad. De hecho puede considerarse herencia del mundo romano, siendo precisamente durante el período de expansión imperial cuando se destaquen dos aspectos relacionados entre sí: el aumento de la riqueza de la élite romana y el masivo crecimiento de la esclavitud, que permitirán la transformación de la economía del Imperio en esos momentos ${ }^{1}$. El término que se les daba, servus, será reemplazado en torno al año 1.000 por el de sclavus, que proviene del derecho germánico, para designar de manera muy particular a las poblaciones de regiones específicamente eslavas, aunque su uso se extienda a otras procedencias, como árabes, turcos o griegos ${ }^{2}$. Tras su declive durante la Edad Media tomará un nuevo e importante impulso a partir del siglo XV, debido al naciente capitalismo, una creciente demanda de mano de obra y la exploración del África negra, que permitirá satisfacerla ${ }^{3}$. África se convertirá en la gran fuente de abastecimiento ${ }^{4}$, prácticamente inagotable, de esclavos, y no por cuestiones raciales, sino económicas, estando detrás de todo ello los bajos costes de su trabajo, muy inferior al de los indios. Además, la fortaleza, docilidad y capacidad de trabajo del negro era muy superior, y no sólo más barato, sino también mejor ${ }^{5}$.

Entre los muchos medios empleados por el poder blanco para mantener al africano y afroamericano como subordinado destaca el argumento de que era

\footnotetext{
1 Keith Hopkins, Conquistadores y esclavos, Barcelona, Península, 1981, págs. 19-27 y 139.

2 Marcel Dorigny y Bernard Gainot, Atlas des esclavages. De l'Antiquité à nos jours, Paris, Autrement, 2013, pág. 6.

3 Antonio Domínguez Ortiz, La esclavitud en Castilla en la Edad Moderna y otros estudios de marginados, Granada, Comares, 2003, pág. 1.

4 Alonso de SAndoval, Un tratado sobre la esclavitud, Madrid, Alianza, 1987, pág. 142. En el capítulo XVII señala los puertos de donde ordinariamente solían salir los esclavos: Guinea, Cabo Verde, isla de Santo Tomé y Angola. El continente africano será una fuente de abastecimiento inagotable, frente a la limitada de los indios. Eric Williams, Capitalismo y esclavitud, Madrid, historia 12, 2011, pág. 36.

5 Eric Williams, Capitalismo y esclavitud, Madrid, historia 12, 2011, pág. 49.
} 
una criatura biológicamente inferior. Realmente, en lo referente al pensamiento y los argumentos sobre la esclavitud en el siglo XVI, ésta se consideraba como un hecho lícito y legítimo, acorde con la naturaleza y las leyes, admitida por la Iglesia, por el derecho civil y el canónico, por los filósofos, los teólogos, los juristas y las costumbres y usos de muchos pueblos ${ }^{6}$. Considerada justa en sí misma, siempre se alzaba alguna voz discordante que dejará escasa huella ${ }^{7}$. Un deterioro considerable de la imagen de los esclavos negros también se aprecia desde el punto de vista literario, en las obras escritas por blancos, y de manera muy especial a partir de la década de $1880^{8}$.

\section{Antecedentes}

Abundan los datos al respecto en toda la península ibérica, siendo ya los esclavos, negros y musulmanes, muy abundantes de manera especial en Andalucía, antes incluso de que los portugueses los introdujesen en gran número procedentes de las costas de Guinea, vendidos en la capital hispalense. En una fecha tan temprana como hacia 1250 ya se encuentran mercaderes moros que ofrecían esclavos negros de Guinea en la feria portuguesa de Guimarães, vendiéndose a finales de siglo en la ciudad de Cádiz. También resultaban bastante numerosos en Barcelona a mediados del XV, como para formar una cofradía religiosa, a la manera de las existentes en las ciudades de Sevilla y Valencia ${ }^{9}$. En poco tiempo, ya desde comienzos del siglo XVI, el negro se había vuelto un componente visible de la sociedad portuguesa, y todos los años las carabelas desembarcaban importantes contingentes de esclavos, cifrados entre 2.000 y 3.000, si hacemos caso de los comentarios del veneciano Lunardo de Cà Masser ${ }^{10}$. No se puede decir lo mismo del resto de España, resultando mucho más escasos en el centro de la península e incluso en el norte, donde llegaban a resultar verdaderas rarezas ${ }^{11}$. Esto explica las

\footnotetext{
6 Aurelia MARTín CASAREs, "Esclavitud y mentalidad: la población esclava de Granada a lo largo del siglo XVI", Revista de historia moderna de la Universidad de Granada, núm. 25 (1998), págs. 338-340.

7 Jesús María García AÑoveros, El pensamiento y los argumentos sobre la esclavitud en Europa en el siglo XVI y su aplicación a los indios americanos y a los negros africanos, Madrid, Centro Superior de Investigaciones Científicas, 2000, pág. 206. Entre estas voces discordantes el autor destaca el pensamiento de contadísimos autores, como Juan Bodino en Los seis libros de la República, publicado en Turín en 1590, Bartolomé Frías de Albornoz en su Arte de los contractos, publicada en Valencia en 1573, y Francisco José de Jaca, con su Resolución sobre la libertad de los negros y sus originarios, en el estado de paganos y después ya cristianos, 1681, legajo conservado en el Archivo General de Indias.

8 Carme Manuel, "Introducción”, en Booker T. Washington, Ascenso desde la esclavitud, León, Universidad de León, 1999, págs. 8 y 10.

9 Hugh Thomas, La trata de esclavos, Barcelona, Planeta, 1998, págs. 40-41.

10 Antonio de AlmeIDA Mendes, "Traite des Maures-traite des Noirs, ou les visages de l'esclavage au Portugal (XV-XVI siècles)", en Trabalho forçado africano, Porto, Centro de Estudos Africanos da Universidade de Porto, Campo das Letras, 2006, págs. 13 y 21.

${ }^{11}$ Antonio Domínguez Ortiz, La esclavitud en Castilla en la Edad Moderna y otros estudios de marginados, Granada, Comares, 2003, págs. 4, 9 y 14.
} 
escasas referencias, muy aisladas, en el caso gallego, a pesar de haberse señalado desde los trabajos de uno de los pioneros del tema, Claudio Sánchez Albornoz, a la Galicia de la primera Edad Media como un territorio en el que la esclavitud permanecería más sólidamente instalada que en otros territorios peninsulares ${ }^{12}$. Se han dado a conocer casos especialmente desde el siglo XVI, como los dos esclavos, el uno pardillo, llamado Francisco, marcado en el rostro, mulato o sobre loro el otro, que se llamaba Pedro, vendidos por Juan de Portugalete al señor Diego Maldonado, camarero del arzobispo, en Santiago de Compostela el 10 de octubre de 1521, y ante el mismo notario y en igual año se realizará la venta de otro esclavo, llamado Antonio, color pardo, por Alonso González, asturiano residente en Lisboa, al señor Gómez del Barral, Justicia de la ciudad. Se conocen más casos, como en 1576, cuando se venden dos negras, la una Juliana, la otra Esperanza, cuyo amo, un portugués, las había comprado en la ciudad brasileña de Santo Tomé, vendiéndolas ahora en el puerto de A Coruña; o en 1583, cuando un juez de la ciudad de Pontevedra compra una esclava nombrada Isabel, de color membrillo, herrada y señalada en el rostro. También entre los peregrinos a Compostela se encuentran esclavos manumitidos, ya en 1560. Los testimonios no cesan en el siglo XVII, pues ya en 1601 un regidor compostelano dictaba en su última disposición mandar liberar a su pareja de esclavos, Jorge e Isabela. En 1624 se habla de un esclavo al servicio de un canónigo compostelano. Y el obispo de Tui dejará a su muerte una esclava a su criada en 1640. Cuarenta años más tarde un capitán de la Armada Naval de Flandes comprará una mulata, a la que liberará al día siguiente. También en Vigo un familiar de la Inquisición comprará un negro en 1688. Incluso en el interior de la provincia lucense, en Vilanova de Lourenzá, un matrimonio dará libertad a su esclava, natural del reino de Portugal, en mayo de 1692. Ejemplos todos ellos recogidos por Pérez Costanti ${ }^{13}$. Más recientemente se ha dado a conocer la existencia de esclavos entre las principales casas de la nobleza gallega durante los siglos XVI y XVII, aunque los negros africanos son una minoría entre los efectivos respecto a los procedentes del mundo musulmán ${ }^{14}$.

\footnotetext{
12 Marcos Fernández Ferreiro, Servos e escravos altomedievais no noroeste da península ibérica, Noia, Toxosoutos, 2009, pág. 7. Señala el autor cómo uno de los conceptos que aparece con cierta frecuencia en la documentación, servus, denomina de forma totalmente explícita a un dependiente servil, siendo la expresión por excelencia para nombrar a los esclavos, pues ese es su significado como entrada latina. Opinión confirmada por otros estudiosos para este período de finales del medievo, como Alfonso FrANCO Silva, "La esclavitud en la península ibérica a fines del medievo. Estado de la cuestión y orientaciones bibliográficas", Boletín de la Sociedad Española de Estudios Medievales, núm. 5 (1995), págs. 201-210. 13 Pablo Pérez Costanti, Historia de Galicia. Notas viejas galicianas, A Coruña, Boreal, 2011, págs. 233-237.

14 Gonzalo Francisco Fernández SuÁrez, "De nación turca, de mediano cuerpo y peli negra: la esclavitud entre la nobleza gallega durante los siglos XVI y XVII”, en M. ${ }^{a}$ Xesús Vázquez y Alexandre Veiga (eds.), Perspectivas sobre Oriente y Occidente. Actas del II curso de Primavera, Lugo, 3-7 de abril de 2005, Lugo, Universidad de Santiago de Compostela, 2008, págs. 55-66.
} 
Pero también tenemos noticias sobre la presencia de esclavos de otras procedencias en tierras gallegas, como los dos asiáticos ${ }^{15}$ vendidos por sendos marineros de las naves de la India de Portugal en la villa de Vigo a finales de septiembre y principios de octubre de 1603. A pesar de los esfuerzos puestos por la corona portuguesa desde el principio para centralizar el comercio de esclavos en Lisboa, lo cierto es que los buques que cargaban esclavos en África no transportaban todo su cargamento a esta ciudad, poniendo rumbo a otros puertos ${ }^{16}$. Se cita siempre el caso de Sevilla, pero como podemos ver no será un caso único. Este comercio esclavista con España no era popular en Portugal, pero se mantendrá dado que el monarca portugués salía beneficiado con estas ventas, al ganar con ellas más dinero que con los impuestos cobrados en su reino ${ }^{17}$.

Aunque pudiera parecer que Galicia quedara al margen del comercio esclavista, lo cierto es que una de las soluciones a la crisis que el comercio colonial sufría en los años finales del Antiguo Régimen será el corso y la trata de negros, decantándose algunos representantes de la burguesía comercial, sobre todo tras la invasión napoleónica, por esta última, especialmente a partir del último cuarto del siglo XVIII, cuando comienza el desmantelamiento de las débiles bases sobre las que se asentaba la estructura del comercio colonial gallego, dependiente en gran medida de la reexportación de textiles, como el resto de España, saturando el mercado con la consiguiente bajada de precios y la ruina de muchas de estas empresas. A estos factores habría que sumar, a partir de 1787, el estallido de una nueva guerra naval con la Gran Bretaña, que se prolongará hasta 1801, bloqueando la salida de navíos desde los puertos españoles, suplantados por barcos de países neutrales, no participantes en la contienda, que pasarán a abastecer las Indias sin la mediación de los puertos peninsulares. Este conjunto de circunstancias adversas provocará el colapso del puerto herculino, hasta entonces el de mayor peso específico entre los gallegos habilitados, pasando de controlar el $96 \%$ de este tráfico al 49,4\%, aumentando la participación de otros, como Vigo o Ferrol, que llegarán a superarlo. Esto afectará profundamente a las pequeñas empresas, muchas de las cuales acaban por desaparecer, lo mismo que a las grandes sociedades, afectadas por un fuerte endeudamiento. Las reacciones ante la crisis serán diversas, siempre excepcionales, y así como algunos optan por el corso, otros $<<$ se aplicarán preferentemente, sobre todo tras la invasión francesa, a la trata de negros $>>$. Carentes de las infraestructuras necesarias en los primeros momentos, la situación dará un giro a partir de 1807, tras la abolición de la trata en Gran Bretaña, lo que provoca

\footnotetext{
15 Caroline Ménard, "Un esclavo que se llama Antonio: venta de dos esclavos asiáticos en Galicia a inicios del siglo XVII”, Cuadernos de Estudios Gallegos, 59, núm. 125 (2012), págs. 233-244.

${ }_{16}$ William Phillips, La esclavitud desde la época romana hasta los inicios del comercio transatlántico, Madrid, Siglo Veintiuno de España Editores, 1985, pág. 234.

${ }^{17}$ H. Thomas, La trata ..., pág. 73.
} 
el desmantelamiento del tráfico inglés, proporcionando así a los comerciantes españoles la infraestructura necesaria. De 1816 a 1820 será la época dorada de la trata española en Cuba, introduciendo esclavos negros, organizándose en A Coruña diversas expediciones negreras a África. Aunque han sido destruidas casi todas las fuentes públicas que podían aportar una información directa sobre el asunto, buscando de esta forma ocultar el origen de las fortunas de algunos de estos descendientes de negreros, mayor ventura se ha tenido con la documentación privada: los fondos de los colegios notariales, con protocolos que nos informan de las escrituras de propiedad y matriculación de navíos negreros, sus características, precios, destinos y cargamentos. El más importante de los negreros gallegos, el armador coruñés Juan Francisco Barrié, que participará en el mayor número de expediciones a África, se referirá en 1816 a la buena relación entre inversiones y beneficios, al no ser necesaria una gran inversión para el tráfico de esclavos ${ }^{18}$. Señala el autor que en Galicia no puede hablarse de un tráfico temprano, tal como aseguraba algún estudioso ${ }^{19}$, al no contar hasta la segunda década del XIX con la infraestructura adecuada.

Adentrándonos en el siglo XVIII, sabemos que el concejo de Santiago contará con un moreno que le serviría de esclavo y en ejercicio de clarinero de la ciudad. Lo adquiere tras fugarse a Galicia escapando de los malos tratos que le proporcionaba su anterior propietario, para quien había servido primero en Brasil y más tarde en Portugal ${ }^{20}$. Esa misma profesión, de clarín de la ciudad, la desempeñará con anterioridad, desde 1718, un esclavo negro en la ciudad de Ourense. Adquirido por el ayuntamiento a un portugués, serviría de trompeta, además de oficiar de sayón y verdugo. Años después, en 1771 el consistorio acordará fundir una argolla de plata, al no haver oy esclavo, para emplear en una nueva escribanía. Al ser examinada por el contraste de plateros se observará que no era de ley, por lo que se volvería a recoger en el archivo $^{21}$.

\footnotetext{
$\overline{18}$ Luis Alonso Álvarez, Comercio colonial y crisis del Antiguo Régimen en Galicia (1778-1818), O Castro, Sada, Consellería da Presidencia, Xunta de Galicia, 1986, págs. 207-218 y 223-226. Las escrituras de propiedad y matriculación de navíos negreros detallan la procedencia de las naves y sus características. En las fianzas en concepto de patente aparece siempre el destino de la embarcación y su carga, mientras que los contratos de tripulación permiten conocer el destino de las embarcaciones, los sueldos y condiciones de los tripulantes. Juan Francisco Barrié participará con 13 expediciones, muy lejos de otros con 3 o 4, como Marcial del Adalid o Salvador Rivera e Hijo. Los primeros navíos gallegos dedicados a la trata serán de procedencia extranjera, e incluso los primeros realizados exprofeso para este tráfico, ya en 1816, construidos en los arsenales de Nantes. Estaban diseñados específicamente para tal fin, bautizándose a uno de los de mayor precio y tonelaje, un bergantín, como El mulato herculino.

19 José Ramón Barreiro Fernández, Historia de la ciudad de La Coruña, A Coruña, La Voz de Galicia, 1986, pág. 358.

20 P. Pérez Costanti, Historia de Galicia ..., págs. 233-237.

${ }_{21}$ Marcelo Macías, "La argolla del esclavo", Boletín de la Comisión de Monumentos de Orense, núm. 185 (1929), págs. 340-341.
} 
El hecho de no resultar frecuente la presencia de esclavos negros en la provincia lucense no quiere decir que resultasen extraños. La ciudad de Lugo, como paso prácticamente obligado entre A Coruña y la corte, verá circular todo tipo de personas y comitivas, incluso el famoso tesoro de Rande. En una de ellas, que atraviesa la ciudad a comienzos de octubre de 1657, figuraba el marqués de Aitona, gobernador y capitán general que había sido del reino, acompañado por su séquito, mandando librar en tal ocasión el ayuntamiento a Juan de Roy, su portero, 108 reales, gasto de la carroza y esclavos de su excelencia para proveerlos del necesario alojamiento ${ }^{22}$.

\section{UN ESCLAVO NEGRO EN LUGO}

Es precisamente a principios del siglo XVIII cuando tenemos constancia de la existencia de un esclavo negro en la ciudad de Lugo, noticia desconocida hasta ahora. No dejamos de destacar su excepcionalidad, pues es el único caso constatado desde mediados del siglo XVI en adelante, hasta el siglo XX, tras la consulta de las actas del consistorio, las del cabildo catedralicio y los protocolos notariales.

En el consistorio ordinario celebrado en las casas consistoriales el 30 de mayo de 1705 se anota al margen: clarín, compra. El documento, muy afectado por la humedad, nos priva de conocer algún dato, pero en lo esencial se nos informa de que hallándose en la ciudad un capitán, que formaba parte del Tercio al mando de un coronel, acuerda vender a la misma un esclavo negro, ajustándolo en 12 doblones. Con tal motivo se pasó escritura de venta ante el escribano ${ }^{23}$, y habiéndose conferido sobre el asunto se acordó aceptar dicha venta, ordenando que el escribano presente supliera en empréstito tal cantidad, de la que más tarde se le daría satisfacción. Visto el asunto, se acordó que se le acreditasen en su cuenta ${ }^{24}$.

\section{SU POSIBLE PROCEDENCIA}

Resulta curioso comprobar cómo las noticias económicas sobre la manutención y sostenimiento del negro resultan prioritarias sobre las particulares de este sujeto. Salvo casos excepcionales nunca se puede hacer una biografía de estos personajes, al no existir datos de su nacimiento, lugar, familia y hechos más destacados, aunque sólo sea de su vida diaria. En general conocemos la fecha de su compra o de llegada, y los gastos de manutención y vestido, acaso su defunción. No suelen dejar otro rastro. Así, no es hasta principios del año 1708 cuando se le nombra

\footnotetext{
22 Archivo Histórico Provincial de Lugo (en adelante AHPLu), Actas, Ayuntamiento, libro núm. 15.

${ }^{23}$ Los esclavos se volvían propiedad del nuevo señor, siendo registrados. José CAPELA, Donas, senhores e escravos, Porto, Afrontamento, 1995, pág. 193.

24 AHPLu, Actas, libro núm. 35, consistorio del 30 de mayo de 1705.
} 
e identifica por su apellido, el Sosa criado de la ciudad ${ }^{25}$. No será hasta un año después cuando conozcamos su nombre, Manuel Sosa ${ }^{26}$. Con su apellido volverá a quedar referenciado a mediados de 1716 , momento de su muerte ${ }^{27}$. Parece ser lo habitual el asignar nombres civiles a los esclavos registrando un único apellido, que era el de la familia del amo, aunque en los primeros tiempos los registros notariales solían usar sólo el nombre de pila del esclavo, acompañando el término derivado del color de la piel, como moreno o pardo ${ }^{28}$. Incluso las familias reales, caso de los Borbones españoles, a pesar de desterrar a los enanos y locos que tuvieron los Austrias en la corte española, se quedaron con los negros, siguiendo con la vieja tradición austríaca de bautizarlos con los nombres y apellidos de la real familia, como aquel Alfonso Carlos de Borbón, negro y arquitecto, en tiempos de Carlos III, monarca que al parecer ponía especial cuidado paternal para con ellos ${ }^{29}$. En nuestro caso el apellido Sosa nos lleva a pensar en su origen portugués, lo que se explicaría en su momento por el hecho de que su propietario, capitán del ejército, sin duda se encontraría luchando en la frontera galaicoportuguesa por aquellas fechas, pues en mayo de 1705 las actas del consistorio recogen abundantes noticias al respecto, como la continuación de la leva, encaminándose la gente de la provincia de Lugo a la villa de A Guarda, debiendo hacer frente las autoridades a gastos para vestir a los soldados. El 31 de diciembre una carta de la ciudad de Ourense y otra del capitán general advierten hallarse con repetidas noticias de que el ejército enemigo, compuesto por más de más de 1.000 hombres de infantería, caballería y artillería se hallaba a punto de marchar en la cercanía de la villa portuguesa de Chaves, existiendo recelos de que viniesen atacar las localidades de Monterrei y Verín ${ }^{30}$. La introducción de esclavos a través del reino de Portugal no es nada nuevo, al contrario, pues tras la encendida polémica entre los monarcas castellano y portugués, las rutas africanas al sur de las Canarias quedaron en manos del segundo, explicando que los beneficios de ese comercio estuviesen regulados por el rey, estableciéndose desde un primer momento el sistema de asientos para la traída de negros, lo que se conocía como el trato del rey de Portugal. Situación que determinará el paso obligado de los negros por este país, en su inicial etapa

\footnotetext{
${ }_{25}$ AHPLu, Actas, libro núm. 37, consistorio del sábado 13 de enero de 1708, fol. 14.

26 AHPLu, Actas, libro núm. 38, consistorio del viernes 25 de enero de 1709.

27 AHPLu, Actas, libro núm. 43, consistorio del sábado 25 de julio de 1716.

${ }_{28}$ Michael Zeuske, "Sin otro apellido". Nombres esclavos, marcadores raciales e identidades en la transformación de la Colonia a la República, Cuba, 1879-1940”, Tzintzun, Revista de Estudios Históricos, núm. 36 (2002), pág. 172.

29 José Moreno Villa, Locos, enanos, negros y niños palaciegos: gente de placer que tuvieron los Austrias en la corte española desde 1563 a 1700, México, Presencia, 1930, pág. 28. Se cita la ocasión en que el monarca resuelve que parta para A Coruña uno de sus negros, acompañado de un cabo de escuadra, disponiéndose una calesa para su conducción a dicha ciudad. Con tal motivo se le abonarían 423 reales para gastos al maestro de los Negros del Rey.

${ }^{30}$ AHPLu, Actas, libro núm. 35, consistorios del 9, 16 y 20 de mayo, y el 31 de diciembre de 1705.
} 
europea. Lisboa se convertirá en cabeza del monopolio de este comercio, desde donde se irían diseminando los esclavos por otros reinos ibéricos ${ }^{31}$. En otras zonas de la geografía española fronterizas con Portugal, dada la permeabilidad de la frontera, se han referenciado acontecimientos semejantes. Resulta destacable el caso de Extremadura, región en la cual la mayor parte de esclavos negros en la Edad Moderna procedían del reino vecino. Esto se explica en relación con las formas de aprovisionamiento, siendo Portugal el principal abastecedor de los mercados castellanos. A través de esa frontera compartida circulaban todo tipo de mercaderes, entre ellos los especializados en la trata de esclavos, cuyo origen era, de manera prioritaria, la nación Angola ${ }^{32}$. La adquisición de este esclavo sin duda de origen portugués en plena Guerra de Sucesión por la corona de España se da en un momento en el que uno de los importantes problemas a debatir entre las naciones europeas consistía en saber qué nación tendría el control del llamado asiento de negros, que aunque poseído por los portugueses, era objeto de fuerte controversia. El nuevo monarca español, Felipe V de Borbón, dará la posibilidad a Francia de hacerse con el mismo, repartiéndose las futuras ganancias entre ambos Borbones y el gobernador de la que por entonces era extraordinariamente próspera colonia azucarera de Santo Domingo. Como era de esperar, a resultas de estos arreglos el rey de Portugal se aliará con Inglaterra y los Habsburgo en contra de los Borbones, lo que supondrá un verdadero triunfo para Francia, que buscaba el control del mercado imperial español. Este tratado sin embargo no gozará de popularidad entre los españoles, que disfrutarán haciendo pasar a sus aliados por pequeñas humillaciones, a la vez que establecían trabas ${ }^{33}$.

\footnotetext{
31 Vicenta Cortés Alonso, Esclavos y libertos en los mundos ibéricos, Madrid, Mundo Negro, 2011, págs. $123-124$ y 211.

32 Rocío Periáñez Gómez, La esclavitud en Extremadura (siglos XVI-XVIII), [en línea], Cáceres, Universidad de Extremadura, 2008, pág. 54, disponible en: http:/www.es/tesis/9788469263150.pdf [Consulta: 22/02/2016]. Otras potencias marítimas europeas participarán de este comercio, en mayor o menor grado, destacándose cuatro países, al ser los que aseguran más del $90 \%$ del conjunto de la trata atlántica: Portugal, con más de cuatro millones y medio de cautivos, seguido de Inglaterra con dos millones seiscientos mil; España participa con algo más de millón y medio, y por último Francia, con un millón doscientos cincuenta mil. Como puede verse, el caso de Portugal resulta excepcional. M. Dorigny y B. Gainot, Conquistadores $y_{\ldots}$. , pág. 16. Llegará un momento en el que las costas africanas no puedan proveer el número de esclavos que los europeos habían acostumbrado a transportar por tan larga serie de años, lo que explica su penetración en el continente para traer esclavos cuando los barcos llegaban a por ellos. Ya de época avanzada conservamos interesantes descripciones de algunos de estos viajes, como los llevados a cabo por el explorador inglés Mungo Park, muy citado en la obra del español Blanco White, cuando volvía de su primer viaje del interior de África. José María Blanco White, Bosquejo del comercio de esclavos, Sevilla, Alfar, 1999, p. 114. Este sacerdote sevillano, residente en Inglaterra desde 1810, resulta una aportación fundamental al debate sobre la esclavitud por parte española. Ferviente defensor de la abolición del tráfico de esclavos, que decretarán las Cortes de Cádiz el 2 de abril de 1811, será luego suprimido este decreto en consideración a las reclamaciones de la ciudad de La Habana, la única que levantó la voz contra aquella medida.

${ }^{33}$ H. Thomas, La trata de..., págs. 225-227.
} 


\section{Su SUSTENTO}

En lo tocante al sustento de dicho esclavo se le señaló un real y medio de alimento cada día, en la renta de propios, al ser necesario dicho clarín para las funciones de la ciudad y saber tocar la caja para los bandos y pregones. Se le daría además por aposento una casa por cuenta de la ciudad, que fuese de poco precio. Un año más tarde, el lunes 1 de marzo de 1706, se vio un memorial de don Juan de Pradeda en el que pedía los 720 reales de 12 doblones que había prestado para la compra de un negro que servía de clarín a la ciudad ${ }^{34}$. Aunque propiedad de una institución, como es el ayuntamiento, lo diferenciaba de otras pertenencias o cosas el hecho de ser un humano, y como tal contaba con deberes y derechos que marcarán su existencia. Los propietarios estaban obligados a respetarles la vida y favorecer su salvación, como hijos de Dios ${ }^{35}$. Pero también tenían que protegerlos, alimentarlos y vestirlos. Esto explica los pagos anuales que hace el consistorio para sostenimiento de su esclavo, que comienzan el 6 de marzo de 1706, cuando se libran 12 reales en propios para realizar unos zapatos al negro de la ciudad, referencia habitual cuando de él se habla ${ }^{36}$. Poco después, a principios de junio, se librarán 77 reales de vellón a don Andrés Varela por razón del alquiler de la casa en que vivía el negro, tras haberse cumplido un año, por San Juan ${ }^{37}$. A partir de 1707 se le buscará un nuevo alojamiento, presentándose el 9 de julio un memorial por Domingo de Vilaboa en el que manifiesta haber dado un cuarto de su casa para el negro, concertado por el procurador general, don Pedro de Anguiano, en 4 ducados por año, pidiendo a la ciudad mandarlos $\operatorname{librar}^{38}$. Memorial que seguirá presentando en años consecutivos por la misma cantidad, en que se había ajustado dicho cuarto ${ }^{39}$, hasta 1715 , en que pasa a ocupar otra vivienda, perteneciente a José Fernández, vecino de la ciudad, donde vivía el moreno y su mujer, pidiendo se le manden pagar los 4 ducados convenidos, una vez más por el año que cumplió en San Juan ${ }^{40}$. Es la primera ocasión en que se menciona a la mujer del esclavo. No sabemos cómo llega hasta aquí, si era o no esclava, aunque sería de suponer, y cómo se concierta esta boda ${ }^{41}$. Además

\footnotetext{
${ }_{34}$ AHPLu, Actas, libro núm. 35, del lunes 1 de marzo de 1706.

35 V. Cortés Alonso, Esclavos y libertos..., pág. 227.

36 AHPLu, Actas, libro núm. 35, consistorio del sábado 6 de marzo.

37 AHPLu, Actas, libro núm. 35, del 3 de junio.

${ }_{38}$ AHPLu, Actas, libro núm. 36, consistorio del sábado 9 de julio de 1707.

39 AHPLu, Actas, libro núm. 37, consistorio del lunes 31 de julio de 1708.

40 AHPLu, Actas, libro núm. 42, consistorio del sábado 17 de agosto de 1715 .

${ }^{41}$ Las noticias sobre la morena son muy escasas, sin apenas prestarle atención, por lo que no tenemos apenas noticias suyas, a pesar de la importancia que a nivel numérico llegaron a ejercer sobre los esclavos, fruto sin duda del uso sexista del lenguaje, como nos deja ver Aurelia MARTín CASARES, "Esclavitud y género en la Granada del siglo XVI”, Arenal. Revista de historia de mujeres, vol. 7, núm. 1 (2000), pág. 43. También de la misma autora "Repensar la esclavitud en el mundo hispano: reflexiones y propuestas metodológicas desde la antropología histórica”, en Aurelia Martín Casares (coord.), Esclavitudes hispánicas (siglos XV al XXI): horizontes socioculturales, Universidad de Granada, 2014, págs. 35-37.
} 
de satisfacer las necesidades básicas de los esclavos, sus amos debían mostrarse propicios a que se casaran, tal como establecían las Leyes de Indias al respecto, procurando que los negros se casasen con negras, y que los esclavos no perdiesen tal condición por haberse casado, convirtiéndose en libres ${ }^{42}$. A pesar de ello, los matrimonios entre esclavos eran muy escasos, ya que dadas sus condiciones de vida resultaba difícil mantener una familia estable, como puede observarse con carácter común tanto en la geografía española como portuguesa, destacándose entre las causas la oposición de los amos, aún a sabiendas de que en caso de conflicto los jueces raramente fallarían en su favor, poniendo de manifiesto el reconocimiento del derecho que tenía el esclavo a poder casarse incluso contra la voluntad de sus señores, tal como aparecía recogido en Las Partidas, legislación que en esta materia se mantendrá en plena vigencia hasta la abolición de la misma ${ }^{43}$. La legislación eclesiástica concordaba en este sentido, como recoge San Antonio Florentino al reproducir lo establecido por la misma acerca de que los esclavos eran libres de contraer matrimonio con quienes quisieran ${ }^{44}$. A pesar de ello, los dueños siempre se opondrán de forma más o menos abierta a estos matrimonios, porque esta circunstancia impedía con posterioridad una posible venta libre, anteponiendo por ello sus propios intereses a la legislación ${ }^{45}$.

También habrán de disponer las autoridades un gasto para vestir al negro, acordándose en 1707 que don José Froilán Baamonde, al hallarse desnudo el negro clarín, encargase un vestido entero, sacándolo a su crédito, y dando cuenta en otro consistorio se le libraría el importe y $\operatorname{coste}^{46}$. A finales del año siguiente, por septiembre, se verá por las autoridades municipales un memorial de Juan Picado en el que pide se le den 15 reales que se habían dado al procurador para zapatos y medias del esclavo de la ciudad. Solicita se despache libranza sobre el salario que diariamente está pagando a dicho esclavo. Dirá haber pagado al esclavo la cantidad de 406 reales de vellón, desde el primero de enero hasta el día de la fecha (22 de septiembre), a razón de real y medio cada día, conforme lo tenía señalado la ciudad ${ }^{47}$.

\footnotetext{
$\overline{42}$ V. Contés Alonso, Esclavos y libertos..., pág. 227, cita la Ley 5, título 5, libro 7 de la Recopilación. Hay que señalar el hecho de que la proporción de matrimonios de esclavos varió de nación a nación y de región a región, siendo mayoritarias las uniones entre esclavos no legalizadas, lo que no quiere decir que no existieran. Era muy habitual que viviesen en unión consensual, formalmente reconocida como una unidad familiar. Herbert KLEIN, La esclavitud africana en América Latina y el Caribe, Madrid, Alianza, 1986, pág. 111.

43 R. Periáñez Gómez, La esclavitud en Extremadura ..., págs. 304-307.

44 Jesús María García AÑoveros, El pensamiento y los argumentos sobre la esclavitud en Europa en el siglo XVI y su aplicación a los indios americanos y a los negros africanos, Madrid, Consejo Superior de Investigaciones Científicas, 2000, pág. 150.

45 José Luis CoRTÉs López, Esclavo y colono. (Introducción y sociología de los negros africanos en la América española del siglo XVI, Salamanca, Universidad de Salamanca, 2004, pág. 226.

${ }^{46}$ AHPLu, Actas, libro núm. 36, consistorio del miércoles 31 de agosto de 1707, fol. 208 y 208 v.

47 AHPLu, Actas, libro núm. 37, consistorio del sábado 22 de septiembre de 1708.
} 
En 1710 se anotará el pago de 16 reales, coste de dos camisas hechas para el esclavo, mientras que en 1711 se invertirán 154 reales y medio para su vestido ${ }^{48}$. Y en 1715 don Andrés Mosquera presentará una cuenta de lo gastado con el negro, en conformidad con el acuerdo del día 10, que sumaba un total de 82 reales de vellón, pidiendo su satisfacción ${ }^{49}$.

\section{Sus ACTIVIDADES}

En el caso lucense la élite de la ciudad, representada por el ayuntamiento, buscaba ostentar una pretendida riqueza, dando una imagen de diferenciación sobre el resto de los habitantes, y una manera de hacerlo era a través de pertenencias que se exhibían y dejaban ver tanto en el día a día como en acontecimientos señalados. No es extraño que se le encargue al esclavo el oficio de clarín, pues ya hemos visto que en el caso gallego esto resultó frecuente. Pero también está constatado en otras ciudades hispanas, como en las ciudades navarras de Pamplona, Olite y Tafalla en el siglo XVIII. En el primer ejemplo entre los cargos asistenciales de la corporación se cita el de clarinero, que acudía a las manifestaciones públicas de la corporación de acuerdo con la solemnidad y el protocolo requeridos ${ }^{50}$. También en la población extremeña de Trujillo se empleó un esclavo negro como pregonero en 1648, señalándose también Extremadura como un territorio más en el que la esclavitud se relaciona con los grupos detentadores del poder, siendo la posesión de personas esclavas una muestra de la riqueza y rango social de este grupo ${ }^{51}$. En el caso americano será frecuente la presencia de esclavos africanos como músicos, especialmente como trompetistas, clarineros y atabaleros en el contexto de la música militar y la de ceremonias públicas civiles y eclesiásticas ${ }^{52}$. Dada la relación entre la población esclava negra con la música no es de extrañar la dedicación de muchos de estos esclavos a tal menester. Aunque con sus propias tradiciones musicales africanas, lo cierto es que el esclavo se inserta en una sociedad blanca esclavista, convirtiéndose en intérprete de una música europea, con instrumentos que le resultaban ajenos, como podía ser el clarín. La propia Iglesia los empleó con este fin $^{53}$. Algunos africanos llegarán a destacarse como notables músicos,

\footnotetext{
$\overline{48}$ AHPLu, Actas, libro núm. 38, consistorio del sábado 8 de marzo de 1710; y libro núm. 39, consistorio del sábado 24 de enero de 1711.

49 AHPLu, Actas, libro núm. 42, consistorio del sábado 24 de agosto de 1715.

50 José Fermín Garralda Arizain, "La burocracia del Ayuntamiento de Pamplona del siglo XVIII", Príncipe de Viana, núm. 191 (1990), pág. 39.

${ }^{51}$ R. Periáñez Gómez, La esclavitud..., págs. 227 y 284.

52 Alejandro ToBÓn Restrepo, Ma Eugenia Londoño, Jesús ZapATA, Entre sones y abozaos. Aproximación etnomusicológica a la obra de tres músicos de la tradición popular chocoana, Medellín, Universidad de Antioquía, 2005, pág. 67.

53 Celia Romero García, "Notas europeas para manos africanas. Vientos de chirimías, flautas y bajones en el contexto de la esclavitud negra de la América colonial", Palabras de la ceiba, Revista electrónica
} 
caso del negrito Balta, a quien se le daba tiempo suficiente por la mañana y por la tarde para que practicase el órgano, sin duda aprendido desde niño en las misiones guaraníes $^{54}$. En la liturgia se le daba especial relevancia a la parte musical de la fiesta, muy cuidada por los negros, grandes aficionados a ella, para lo que solían contratar a cantores y músicos de guitarra o vihuela ${ }^{55}$. No debemos olvidar la proverbial disposición del hombre negro para la música, apreciada enseguida, de la que ya testigos excepcionales, como Cervantes, se hacen eco, en obras como El celoso extremeño ${ }^{56}$. Se ha querido ver cómo la música y la danza tenían una gran importancia para los negros, al representar el único eslabón que todavía los unía con la cultura que habían dejado atrás, sirviéndoles, por otra parte, como elemento de socialización ${ }^{57}$. Los portugueses enseguida advirtieron el gusto que por la música sentían los esclavos africanos, por lo que alentaron la formación en Lisboa de bandas africanas de tambores y flautistas ${ }^{58}$. Estas funciones musicales de los negros explica su participación en desfiles y ceremonias, formando parte de comitivas en las que iban primero los negros atabaleros y tras ellos muchos clarines, cajas, trompetas y chirimías, como ocurrió en la entrada del capitán Pedro Luis Enríquez, antiguo corregidor de La Paz entre 1674 y 1678, al ser trasladado a Potosí con igual cargo y hacer su ingreso en la misma. Sumémosle a ello la apariencia cargada de exotismo, al ser usado como un ingrediente de color y vistosidad en este tipo de $\operatorname{actos}^{59}$.

Pero además de clarín, el negro de Lugo realizaba también otras actividades, por las que recibía un estipendio, como los 6 reales por la limpieza de fuentes en la ciudad ${ }^{60}$ en 1709 . También, anualmente, recibía un aguinaldo a principios de enero, aunque no lo hemos encontrado reseñado todos los años que permaneció

de la Fundación de Cultura Afrohispanoamericana [en línea], disponible en $<$ http://palabrasdelaceiba. es/revistas-home > [Consulta: 22/02/2016].

${ }^{54}$ Carlos PAge, "Hacia la consideración de una arquitectura afro-jesuítica en la antigua provincia del Paraguay”, Anales del Museo de América, núm. XX (2012), pág. 169.

55 Rafael Ortega SAgrista, "La cofradía de los negros en el Jaén del siglo XVII", Boletín del Instituto de Estudios Giennenses, núm. 12 (1957), pág. 129.

56 J. L. CoRTés LóPez, Esclavo y..., pág. 98.

57 Antonio Santos MoRILlo, "Caracterización del negro en la literatura española del XVI", Lemir. Revista electrónica de Literatura Española Medieval y del Renacimiento [en línea], núm. 15 (2011), disponible en < http://parnaseo.uv.es/lemir.htm > [Consulta: 22/02/2016].

${ }_{58}$ H. Thomas, La trata..., pág. 63. Estos esclavos trajeron a Portugal algo de su música y algunos bailes.

59 Alberto Crespo Rodas, Esclavos negros en Bolivia, La Paz, Academia Nacional de Ciencias de Bolivia, 1977, pág. 10. Desde los primeros tiempos, a partir del siglo XVI, se constata en la América hispana la presencia de esclavos negros en múltiples ámbitos, como el trabajo de la tierra o en la minería, pero también desarrollando su labor en las instituciones y comunidades. Los había que eran propiedad de audiencias, gobernaciones, ayuntamientos y otras corporaciones públicas de carácter político y administrativo, desempeñando el papel de pregoneros y otros cargos municipales de poco rango. J. L. CoRTÉs LóPEZ, $L a$ esclavitud negra..., págs. 136 y 178.

${ }^{60}$ AHPLu, Actas, libro núm. 38, consistorio del sábado 29 de junio de 1709. Se le pagan al esclavo junto con el oficial público, debiendo darse testimonio de la citada cantidad al procurador. 
al servicio de la ciudad. Así, en 1708 recibirá 12 reales por este concepto, los mismos que en 1709 y 1713 , que quedan reducidos a tan sólo 8 reales en 1715 y $1716^{61}$. Y también como responsable del esclavo, la ciudad tenía que hacer frente a imprevistos en los que este se vio involucrado. Es el caso de una muerte, quizá accidental, de la que apenas nada se reseña en las actas del consistorio. Este ha de sacar 100 reales de vellón en mayo de 1707, por cuenta de la propina del Corpus, para el entierro de la pobre que murió con la desgracia del negro. Cantidad que será librada para el entierro de la difunta que mató el negro desgraciadamente ${ }^{62}$. Otras ocasiones eran más felices, sirviendo para prestigiar a la ciudad, como ocurre en 1715 cuando en el consistorio celebrado el sábado 10 de agosto se recibe una petición por parte de don Jacinto Antonio Enríquez, regidor de la villa de Monforte de Lemos, solicitando se le prestase el moreno para asistir a las fiestas de Nuestra Señora de la Asunción. Se acordará escribirle ofreciéndoselo, y para ello don Andrés Mosquera debería encargar la confección de una chupa de paño y lo más que necesitase, que con relación de su coste se le daría satisfacción ${ }^{63}$. El prestar a los clarineros puede decirse que entraba dentro del cargo. En Navarra se ha reseñado cómo, en ocasiones y a petición de otras ciudades, la corporación prestaba el servicio de sus clarineros para ciertas funciones públicas, como ocurrió con las ciudades de Olite y Tafalla con objeto de la aclamación de Fernando VII de Navarra en 1700, o por las fiestas de Tafalla en 1707. Recibían para la ocasión la librea o vestido que debían utilizar en estas funciones públicas ${ }^{64}$.

Como podemos ver, los trabajos desempeñados por nuestro protagonista no eran exigentes, a pesar de que a los esclavos les estaba prohibida toda labor no mecánica. El ser destinado a una ciudad solía provocar distinta suerte respecto a una ocupación como trabajador agrícola o minero por ejemplo. Un esclavo urbano solía servir como doméstico o aplicado a un oficio ${ }^{65}$. Por eso la condición de un esclavo variaba en función de la actividad que desempeñaba, pues no era lo mismo estar destinado al servicio doméstico o a trabajos artesanales que en trabajos agrícolas y mineros, lo que explica unas esperanzas de vida muy variables ${ }^{66}$. Siempre hubo excepciones, siendo posiblemente una de las más destacadas la de un notorio pintor, Juan de Pareja, eclipsado por su maestro, Diego Velázquez, quien lo efigiará en un famoso retrato conservado en la actualidad en el Museo

\footnotetext{
${ }^{61}$ AHPLu, Actas, libros núm. 37, 38, 41, 42 y 43, consistorios del sábado 13 de enero de 1708, fol. 14, viernes 25 de enero de 1709, sábado 21 de enero de1713, fol. 16, sábado 19 de enero de 1715 y sábado 18 de enero de 1716.

62 AHPLu, Actas, libro núm. 36, consistorio del sábado 14 de mayo, fol. 122, y del 25 de junio de 1707 , fol. 162 .

63 AHPLu, Actas, libro núm. 42, consistorio del sábado 10 de agosto de 1715.

64 J. F. Garralda Arizain, "La burocracia...”, págs. 40-41.

65 J.A. Piqueras, La esclavitud..., pág. 199.

${ }^{66}$ A. Almeida Mendes, “Traite des...”, pág. 25.
} 
Metropolitano de Nueva York. Copiaba algunas de las obras de su amo, y en cierta ocasión, según nos cuenta Palomino, cuando Felipe IV curioseaba las obras de su pintor de cámara se percató de un cuadro puesto de espaldas. Al volverlo, Juan de Pareja se arrojó a sus pies, confesando ser su autor, solicitando no ser castigado. Tuvo efecto poco después el desenlace, dándole finalmente Velázquez carta de libertad ${ }^{67}$.

\section{EL ESCLAVO COMO SÍMBOLO DE ESTATUS}

A partir del siglo XVI se asiste a un incremento destacado de los esclavos negros en el mundo peninsular, desempeñando especialmente trabajos domésticos, así como en todo tipo de oficios. Poseían esclavos los aristócratas, los profesionales ricos y las instituciones, convirtiéndose los africanos en el segmento más numeroso al ir desapareciendo los moros y otros grupos de manera progresiva ${ }^{68}$. No dejaba de ser un signo de prestigio social ${ }^{69}$, pues en todos los casos poseer esclavos fue siempre un símbolo de posición. Ciudades como Sevilla llamarán pronto la atención a propios y extranjeros por los numerosos esclavos que en ella se encontraban, indicativos de la gran riqueza que atesoraba la ciudad, estando asimismo considerados entre los artículos más lujosos. Esto se acentuará tras el descubrimiento y colonización de América, que representará una gran competencia para el mercado peninsular, en el que los esclavos se relegarán al servicio doméstico en las casas principales, y por emulación a las que buscaban aparentar ${ }^{70}$, lo que sin duda puede hacerse extensivo a instituciones, como el ayuntamiento lucense. Ese afán de notoriedad y prestigio que daba un esclavo negro será también empleado en la imagen pública de los miembros de la realeza, formando parte de retratos en los que acompañan al protagonista. Sirva de ejemplo el retrato de Juana de Austria, invención probable del pintor flamenco Antonio Moro que hoy conocemos a través de una copia del portugués Cristóbal de Moura, conservado en los Museos Reales de Bruselas, que los historiadores fechan entre 1552 y $1553^{71}$.

\footnotetext{
$\overline{67}$ Juan M. SAN Miguel, ;Esclavos!, Madrid, SM, 1989, pág. 34.

${ }^{68}$ H. KLeIn, La esclavitud..., págs. 21-22.

69 Ya en el mundo mediterráneo medieval la esclavitud tuvo un carácter de servicio doméstico y a la vez que los esclavos servían a sus dueños les proporcionaban prestigio y el mantenimiento de una apariencia social lujosa. Alfonso Franco Silva, "La esclavitud en Castilla durante la Baja Edad Media: aproximación metodológica y estado de la cuestión”, Historia. Instituciones. Documentos, Universidad de Sevilla, núm. 6, 1979, pág. 119.

${ }^{70}$ José Antonio Piqueras, La esclavitud en las Españas. Un lazo trasatlántico, Madrid, Catarata, 2012, págs. 38,39 y 43 .

${ }_{71}$ Fernando MARÍAS, "La representación del heredero: la imagen del príncipe de Asturias en la España de los Austrias”, en Silke Knippschild y Víctor Manuel Mínguez (coords.), Ceremoniales, ritos y representación del poder, Castellón, Universitat Jaume I, 2005, págs. 134-135.
} 
En él Juana de Austria se hace acompañar de un pequeño servidor de raza negra, interpretado como alusión explícita a los dominios portugueses, subrayando la alta condición de la princesa ${ }^{72}$. En el caso del retrato del príncipe Felipe IV y el enano Miguel "Soplillo", por Rodrigo de Villandrando, se representa al heredero como un infante que protege a un ser de los considerados social e incluso humanamente inferiores ${ }^{73}$. Incluso el primer Borbón, Felipe V, nada más acceder al trono hispano se hace representar ataviado con el severo traje negro español acompañado, en un aparatoso escenario, por un enano negro, entre otros accesorios, en un cuadro de Antonio Palomino ${ }^{74}$. En otras representaciones pictóricas novohispanas, como son los abundantes biombos decorados con vistas y acontecimientos ocurridos en diversas capitales, los negros hacen acto de presencia, formando parte de las comitivas o acompañando a sus amos, como podemos ver en el biombo con la representación del palacio de los virreyes de México, obra del siglo XVII, o aquel en que se representa la entrada del virrey Rubio Morcillo en Potosí, pieza de Melchor Pérez de Holguín, de 1716, en ambos casos pertenecientes al madrileño Museo de América ${ }^{75}$. En estos paseos criollos y españoles se acompañaban por sus esclavos bien vestidos, para así exhibir su prestigio ${ }^{76}$. La presencia de negros en este tipo de obras supone un claro avance respecto a las Edades Media y Moderna, cuando la aparición del negro se circunscribía básicamente a las representaciones religiosas, como la descripción del infierno o el rey Baltasar en la Adoración de los Magos $^{77}$. Observemos sin embargo cómo, a pesar de la aparición de esclavos negros en estas imágenes, no nos resultan reconocibles, al desconocer sus nombres o cargos, pues no dejan de ser elementos complementarios para dejar ver la importancia del personaje central, el auténtico protagonista, sea un virrey o un monarca. Por eso resulta poco menos que imposible encontrar algún retrato de este tipo de personajes. Un caso sorprendente en este sentido, si no único, son las representaciones de carácter naturalista que el pintor holandés Albert Eckoud nos dejó para documentar la fauna, la flora y los tipos étnicos que

\footnotetext{
72 Leticia Ruiz Gómez, "En nombre del Rey. El retrato de Juana de Austria del museo de Bellas Artes de Bilbao", Boletín del museo de Bellas Artes de Bilbao, núm. 2 (2007), págs. 9.

${ }^{73}$ F. MARÍAs, "La representación...", págs. 133-134.

${ }^{74}$ Cuadro conservado en el Paraninfo de la Universidad de Salamanca. Jesús UrREA, "Nuevas obras de Don Antonio Palomino", Boletín del Seminario de Estudios de Arte y Arqueología, núm. 49 (1983), pág. 494.

75 Ministerio de educación, Cultura y Deporte, www.mecd.es/museodeamerica/colección, núm. de inventario MAM 00207 y MAM 00087.

76 Cristina Masferrer León, "Niños y niñas esclavos de origen africano en la capital novohispana (siglo XVII)”, en M. ${ }^{a}$ Elisa Velásquez (dir.), Debates históricos contemporáneos: africanos y afrodescendientes en México y Centroamérica, México, Centro de Estudios mexicanos y centroamericanos, 2011, pág. 218. 77 Luis Méndez Rodríguez, "La esclavitud a través del arte", en Andrés Gutiérrez y Beatriz Robledo (coord.), Laberintos de libertad. Entre la esclavitud del pasado y las nuevas formas de esclavitud del presente, Madrid, Ministerio de Educación, Cultura y Deporte, 2011, pág. 45.
} 
habitaban Pernambuco en el período de dominio holandés en parte del Brasil, conocido como nassoviano ${ }^{78}$.

Si bien muchas de aquellas personas estaban deseosas de comprar y poseer esclavos para, de alguna forma, poder vivir de acuerdo a las costumbres del momento, ya en el segundo tercio del siglo XVIII aparece la figura de John Woolman, ferviente opositor al sistema esclavista, que consideraba que tales prácticas encerraban trazas de lujo, puesto que en su opinión cuando nos apartamos del uso apropiado que Dios estableció para sus criaturas, es ahí donde empieza el lujo ${ }^{79}$.

\section{DESAPARICIÓN DE NUESTRO PROTAGONISTA}

Entre enero y julio de 1716 desaparece nuestro protagonista. No se recogen en las actas del consistorio las noticias de su fallecimiento y entierro. Sin embargo, sabemos de su muerte por su viuda, a la que ahora ya ponemos nombre, Isabel Francisca, al haber enviado un memorial en el que suplicaba a la ciudad sirviese mandarle librar el salario que le había quedado debiendo a su marido. Se acordará poner un decreto a continuación de dicho memorial que sirviera de libranza sobre los efectos de propios de ese año, para que el arrendatario ajustase lo que quedó debiendo hasta el último día de la semana en que murió Sosa, lo que acordaron y firmaron. En el margen puede leerse que a la morena de esta ciudad se

\footnotetext{
${ }_{78}$ Una época en la que, al no disponerse de las actuales facilidades de reproducción llegadas con la técnica fotográfica, se empleaba para ello el talento de los pintores. En este caso también para hacer un inventario iconográfico con el que registrar para los habitantes del Viejo Mundo los paisajes y formas de vida de los habitantes del Nuevo. Todo ello en una fecha tan temprana como 1636, año en el que los directores de la Compañía de las Indias Orientales deciden enviar a Brasil a un gobernador general que consolidase el poder en los nuevos territorios conquistados en tierras brasileñas, buscando el aumento de la producción azucarera, y consecuentemente los beneficios de la compañía. Cargo que recae en la figura de Juan Mauricio de Nassau-Siegen. Resulta interesantísimo observar cómo su administración se va a desenvolver con un concepto bien diferente al adoptado por la mayoría de sus contemporáneos que iban destinados al Oriente. Algo que ya resulta evidente en su salida desde los Países Bajos, a la hora de escoger a los integrantes de su comitiva, no sólo formada por soldados y oficiales, sino también por científicos y artistas. Entre estos últimos se encontraban los pintores Frans Rost y Albert Eckout, con la función de retratista, también para la fauna y flora. Se conservan de su mano cuadros de negros y mulatos, que llaman la atención por su destacado tamaño y la detallada y notable observación etnográfica que hace de los tipos humanos. Elly de VRIEs, "Arte e ciencia no Brasil holandés", Viajando con Eckout: roteiros para viajantes-professores, Recife, Instituto Ricardo Brennand, 2002, págs. 49-51. En 1643/1644 Mauricio de Nassau recibirá la visita de tres embajadas congoleñas, teniendo como objetivos de sus viajes la intervención del gobernador holandés respecto a las divergencias territoriales en el Congo. Estos cuadros, en los que se retrata al embajador Don Miguel de Castro y dos siervos, todos ellos de raza negra, se conservan en la actualidad en el Museo nacional de Dinamarca. Y si bien se reproducen en ocasiones en estudios sobre el tema, lo cierto es que se pasan por alto sus nombres. Porque los conocemos. Los sirvientes se llamaban Pedro Sunda y Diego Bemba. Statens Museum for Kunst [en línea], disponible en: www.smk.dk/en/explore-the-art/highlights/ jaspar-becks-don-miguel-de-castro-emisary-of-congo7 [consultado el 11 de abril de 2016].

79 John Woolman, Consideraciones acerca de la posesión de esclavos. Alegato por los pobres, León, Universidad de León, 2000, pág. 99.
} 
le pague ${ }^{80}$. La viuda todavía enviará un nuevo memorial en los primeros días de enero de 1717, pidiendo que en atención a la fiesta de Reyes se sirviera la ciudad librarle alguna ayuda de costa, accediendo en otorgarle 2 ducados sobre la renta de propios. Esos mismos días José de Ceide enviaba otro memorial suplicando a la ciudad sirviese mandarle pagar los 4 ducados que se le debían por la paga de la casa arrendada en que había vivido el moreno el año anterior, lo que se acordará sobre la renta de propios $^{81}$. La gratificación a las viudas en concepto de pensión vitalicia será un dato recogido también en otros lugares ${ }^{82}$. Llama nuestra atención el hecho de no referirse nota alguna sobre el entierro del esclavo, que sin duda originaría unos costes. No aparece reseñado en los libros de difuntos de ese año en la ciudad. ¿Acaso se enterró en otra parroquia fuera de la capital? A su desaparición no se le da ninguna importancia, como vemos. Su consideración social, interpretamos, era nula.

\section{OTRO NEGRO, NO ESCLAVO, EN LA CIUDAD}

Con la muerte de nuestro protagonista, Manuel Sosa, el esclavo de la ciudad, podría parecer que esta historia tocara a su fin. Nada más lejos de la realidad. Treinta y seis años después, en 1752, la ciudad de Lugo volvía a contar con la presencia de un negro, que también servirá de clarín. Pero en este caso ya no se trata de un esclavo, siendo lo más probable que se tratase de un liberto que, al ser liberado de la esclavitud, podía desempeñar cualquier trabajo que le permitiera vivir $^{83}$. El 11 de marzo de dicho año se acordará en la celebración del consistorio que, tras haberse presentado un moreno llamado Antonio de Silva ofreciéndose servir a la ciudad de clarín, se resolvió que de momento y hasta que la ciudad determinase lo conveniente, se le asistiera con un real diario desde dicho día, que se le libraría en la renta de propios, debiendo entregárselo diariamente el arrendatario hasta nueva orden ${ }^{84}$. Sin duda nuestro nuevo personaje era conocedor de la existencia, tiempo atrás, de un clarín negro en la ciudad, que de esta manera buscaba prestigiarse. Se le sigue denominando tanto negro como moreno, como al anterior, aun cuando algún autor identifica en la América hispana estos nombres con la condición de estas personas, designándose como negro al esclavo en general, sin más precisión, pero los libertos y sus descendientes pasarán a ser conocidos como pardos, en el caso de los mulatos, y morenos los negros libres ${ }^{85}$.

\footnotetext{
$\overline{80}$ AHPLu, Actas, libro núm. 43, consistorio del sábado 25 de julio de 1716.

${ }^{81}$ AHPLu, Actas, libro núm. 44, consistorio del sábado 9 de enero de 1717.

82 J. F. Garralda Arizain, "La burocracia...", pág. 41.

83 V. Cortés Alonso, Esclavos y libertos..., pág. 343.

${ }^{84}$ AHPLu, Actas, libro núm. 77, consistorio del sábado 11 de marzo de 1752. Al margen puede leerse "el negro",

85 J. A. Piqueras, La esclavitud..., pág. 48.
} 
A principios de mayo el consistorio acordará que el señor don Luis Villar encargase una librea entera para el moreno clarín, presentando la relación de su coste, que le sería abonado. La contestación apenas se hace esperar. Se componía el conjunto de casaca, chupa, calzones, medias, zapatos y sombrero, de paño azul con divisa blanca, lo que montaba 243 reales y medio, que se librarían de la renta de propios $^{86}$. Una forma más de exteriorizar la riqueza del propietario, o en este caso de la institución para la que trabajaba. Era habitual que los dueños de esclavos los llevasen armados y vestidos con librea, como escolta de sus amos por las calles $^{87}$, como un signo más de distinción. De la corte de los Austrias españoles se conservan las cuentas particulares de los gastos que ocasionaban la lista de negros, negrillos y niños, fundamentalmente centrados en vestidos, algunos para zapatos y también para raciones ${ }^{88}$.

En los primeros días de junio el ayuntamiento acordará que en adelante, tras el Corpus, se asistiese al moreno con real y medio de vellón por el tiempo que sirviere a la ciudad de clarín además de lo que la ciudad le mandare, lo que diariamente le entregaría el arrendatario de propios, advirtiéndole que de ninguna manera le adelantase el sueldo ${ }^{89}$. Como puede verse el sueldo era muy bajo ${ }^{90}$, exactamente la misma cantidad que se destinaba al sostenimiento del anterior esclavo en 1708. El negro podía ser libre, pero su consideración social seguía siendo muy baja, y tal como apuntan algunos autores se trataría realmente de una libertad restringida, al imponérsele limitaciones por causa de su origen y color ${ }^{91}$. De hecho, entre los escasos defensores de los esclavos negros la preocupación primordial será de carácter espiritual, procurando que ninguno muriera sin haber recibido el bautismo, como se observa en el tratado sobre la esclavitud del jesuita Alonso de Sandoval, testigo de excepción desde su convento cartagenero en la América del XVII ${ }^{92}$. Esto explicaría que poco menos de un año después, en marzo de 1753, tenga lugar la despedida del negro, tal como se anota al margen del libro de actas. Antonio de Silva, negro de la ciudad, había comunicado a la misma que se había presentado un hermano a buscarle, y que no podía seguir sirviéndola por el sueldo que ésta le daba. El consistorio lo da por despedido, previniendo al arrendatario no concurriese con el sueldo ${ }^{93}$. Queda clara la justificación del negro, como ya

\footnotetext{
${ }_{86}$ AHPLu, Actas, libro núm. 77, consistorios del sábado 6 y 20 de mayo de 1752.

87 William Phillips, Historia de la esclavitud en España, Madrid, Playor, 1990, pág. 211.

88 J. Moreno Villa, Locos, enanos..., págs. 150-157.

89 AHPLu, Actas, libro núm. 77, consistorio extraordinario del 8 de junio de 1752.

${ }^{90}$ En 1501 cobraba real y medio de plata al día el negro Alfonso, que acompañaba como criado a la duquesa de Braganza, en Sevilla. Alfonso Franco Silva, "Los negros libertos en las sociedades andaluzas entre los siglos XV al XVI", Los marginados en el mundo medieval y moderno, Almería, 5-7 de noviembre de 1998, pág. 61.

${ }^{91}$ H. Klein, La esclavitud..., pág. 139.

92 A. SAndoval, Un tratado..., págs. 16-32.

93 AHPLu, Actas, libro núm. 77, consistorio del sábado 24 de marzo de 1752.
} 
apuntábamos, ofreciéndosele un trabajo de esclavo, tratado como su predecesor. Pasado el tiempo las cosas parecían seguir igual.

Apuntan algunos historiadores cómo tras llegar a su apogeo la esclavitud en Castilla en los siglos XVI y XVII, decaerá primero lentamente y a partir de principios del XVIII con gran rapidez, de acuerdo con los escasos testimonios conservados. El gran número de trabas lo explicaría, señalando la escasa presencia de negros en España en dicho siglo, que ya no se vendían aquí, aunque se traía alguno en ocasiones de Indias ${ }^{94}$.

\section{BIBLIOGRAFÍA}

Almeida Mendes, Antonio de, "Traite des Maures-traite des Noirs, ou les visages de l'esclavage au Portugal (XV-XVI siècles)", en Centro de Estudos Africanos da Universidade do Porto (coord.), Trabalho forçado africano. Experiências coloniais comparadas, Porto, Campo das Letras, 2006, págs. 13-30.

Alonso Álvarez, Luis, Comercio colonial y crisis del Antiguo Régimen en Galicia (1778-1818), O Castro, Sada, Consellería da Presidencia, Xunta de Galicia, 1986.

Barreiro Fernández, José Ramón, Historia de la ciudad de La Coruña, A Coruña, La Voz de Galicia, 1986.

Blanco White, José María, Bosquejo del comercio de esclavos, Sevilla, Alfar, 1999.

Capela, José, Donas, senhores e escravos, Porto, Afrontamento, 1995.

Cortés Alonso, Vicenta, Esclavos y libertos en los mundos ibéricos, Madrid, Mundo Negro, 2011.

Cortés López, José Luis, La esclavitud negra en la España peninsular del siglo XVI, Salamanca, Universidad de Salamanca, 1989.

Cortés López, José Luis, Esclavo y colono. (Introducción y sociología de los negros africanos en la América española del siglo XVI), Salamanca, Universidad de Salamanca, 2004.

Crespo Rodas, Alberto, Esclavos negros en Bolivia, La Paz, Academia Nacional de Ciencias de Bolivia, 1977.

Domínguez Ortiz, Antonio, La esclavitud en Castilla en la Edad Moderna y otros estudios de marginados, Granada, Comares, 2003.

Dorigny, Marcel; Gainot, Bernard, Atlas des esclavages. De l'Antiquité à nos jours, Paris, Autrement, 2013.

Fernández Ferreiro, Marcos, Servos e escravos altomedievais no noroeste da península ibérica, Noia, Toxosoutos, 2009.

Fernández Suárez, Gonzalo Francisco, "De nación turca, de mediano cuerpo y peli negra: la esclavitud entre la nobleza gallega durante los siglos XVI y XVII", en M. ${ }^{a}$ Xesús Vázquez y Alexandre Veiga (eds.), Perspectivas sobre Oriente y Occidente. Actas del II Curso de Primavera, Lugo, 3-7 de abril de 2005, Lugo, Universidad de Santiago de Compostela, 2008, págs. 55-66.

\footnotetext{
$\overline{94}$ A. Domínguez Ortiz, La esclavitud..., págs. 31 y 37.
} 
Franco Silva, Alfonso, "La esclavitud en Castilla durante la Baja Edad Media: aproximación metodológica y estado de la cuestión”, Historia. Instituciones. Documentos, núm. 6 (1979), págs. 113-128.

Franco Silva, Alfonso, "La esclavitud en la península ibérica a fines del medievo. Estado de la cuestión y orientaciones bibliográficas", Boletín de la Sociedad Española de Estudios Medievales, núm. 5 (1995), págs. 201-210.

Franco Silva, Alfonso, "Los negros libertos en las sociedades andaluzas entre los siglos XV al XVI", en M. ${ }^{a}$ Desamparados Martínez (coord.), Los marginados en el mundo medieval y moderno, Almería, 2000, págs. 51-64.

García Añoveros, Jesús María, El pensamiento y los argumentos sobre la esclavitud en Europa en el siglo XVI y su aplicación a los indios americanos y a los negros africanos, Madrid, Consejo Superior de Investigaciones Científicas, 2000.

Garralda Arizain, José Fermín, “La burocracia del Ayuntamiento de Pamplona del siglo XVIII”, Príncipe de Viana, 191 (1990), págs. 867-940.

Hopkins, Keith, Conquistadores y esclavos, Barcelona, Ediciones Península, 1981.

Klein, Herbert S., La esclavitud africana en América Latina y el Caribe, Madrid, Alianza, 1986.

Manuel, Carme, "Introducción”, en Booker T. Washington, Ascenso desde la esclavitud, León, Universidad de León, 1999.

Macías, Marcelo, "La argolla del esclavo", Boletín de la Comisión de Monumentos de Orense, núm. 185 (1929), págs. 340-341.

Marías, Fernando, "La representación del heredero: la imagen del príncipe de Asturias en la España de los Austrias", en Silke Knippschild y Víctor Manuel Mínguez (coords.), Ceremoniales, ritos y representación del poder, Castellón de la Plana, Universitat Jaume I, 2005, págs. 109-142.

Martín Casares, Aurelia, "Esclavitud y mentalidad: la población esclava de Granada a lo largo del siglo XVI", Chronica Nova, revista de historia moderna de la Universidad de Granada, núm. 25 (1998), págs. 337-348.

Martín Casares, Aurelia, "Esclavitud y género en la Granada del siglo XVI", Arenal. Revista de historia de mujeres, vol. 7, núm. 1 (2000), págs. 41-61.

Martín Casares, Aurelia, "Repensar la esclavitud en el mundo hispano: reflexiones y propuestas metodológicas desde la antropología histórica", en Aurelia Martín Casares (coord.), Esclavitudes hispánicas (siglos XV al XXI): horizontes socioculturales, Granada, Universidad de Granada, 2014, págs. 11-38.

Masferrer León, Cristina, "Niños y niñas esclavos de origen africano en la capital novohispana (siglo XVII)", en M $\mathrm{M}^{\mathrm{a}}$ Elisa Velásquez (dir.), Debates históricos contemporáneos: africanos $y$ afrodescendientes en México y Centroamérica, México, Centro de Estudios mexicanos y centroamericanos, 2011, págs. 195-242.

Meillassoux, Claude, Antropología de la esclavitud, México, Siglo Veintiuno Editores, 1990.

Ménard, Caroline, "Un esclavo que se llama Antonio: venta de dos esclavos asiáticos en Galicia a inicios del siglo XVII", Cuadernos de Estudios Gallegos, 59, núm. 125 (2012), págs. 233-244.

Méndez Rodríguez, Luis, "La esclavitud a través del arte", en Andrés Gutiérrez y Beatriz Robledo (coord.), Laberintos de libertad. Entre la esclavitud del pasado y las nuevas formas de esclavitud del presente, Madrid, Ministerio de Educación, Cultura y Deporte, 2011, págs. 39-71. 
Moreno Villa, José, Locos, enanos, negros y niños palaciegos: gente de placer que tuvieron los Austrias en la Corte española desde 1563 a 1700, México, Presencia, 1930.

Ortega Sagrista, Rafael, "La cofradía de los negros en el Jaén del siglo XVII", Boletín del Instituto de Estudios Giennenses, núm. 12 (1957), págs. 125-134.

Page, Carlos A., "Hacia la consideración de una arquitectura afro-jesuítica en la antigua provincia del Paraguay", Anales del Museo de América, núm. XX (2012), págs. 166-198.

Pérez Costanti, Pablo, Historia de Galicia. Notas viejas Galicianas, A Coruña, Boreal, 2011.

Periáñez Gómez, Rocío, La esclavitud en Extremadura (siglos XVI-XVIII), [en línea], Cáceres, Universidad de Extremadura, 2008, disponible en: http://www.unex.es/tesis/9788469263150.pdf [Consulta: 22/02/2016]

Periáñez Gómez, Rocío, “Cómo se llaman los esclavos en la Extremadura moderna?”, en Gregorio Salinero e Isabel Testón (eds.), Un juego de engaños: movilidad, nombres y apellidos en los siglos XV a XVIII, Madrid, Casa de Velázquez, 2010, págs. 221-228.

Phillips, William, La esclavitud desde la época romana hasta los inicios del comercio transatlántico, Madrid, Siglo Veintiuno de España Editores, 1985.

Phillips, William, Historia de la esclavitud en España, Madrid, Playor, 1990.

Piqueras, José Antonio, La esclavitud en las Españas. Un lazo trasatlántico, Madrid, Catarata, 2012.

Romero García, Celia, "Notas europeas para manos africanas. Vientos de chirimías, flautas y bajones en el contexto de la esclavitud negra de la América colonial", Palabras de la Ceiba, Revista electrónica de la Fundación de Cultura Afrohispanoamericana, 2015, [en línea], disponible en: http://palabrasdelaceiba.es/revistas-home [Consulta: 22/02/2016]

Ruiz Gómez, Leticia, "En nombre del Rey. El retrato de Juana de Austria del museo de Bellas Artes de Bilbao", Boletín del Museo de Bellas Artes de Bilbao, núm. 2 (2007), págs. 85-123.

San Miguel, Juan M., ;Esclavos!, Madrid, SM, 1989.

Sandoval, Alonso de, Un tratado sobre la esclavitud, Madrid, Alianza, 1987.

Santos Morillo, Antonio, "Caracterización del negro en la literatura española del XVI", Lemir, Revista electrónica de Literatura Española Medieval y del Renacimiento [en línea], núm. 15 (2011). Disponible en: http://parnaseo.uv.es/lemir.htm [Consulta: 22/02/2016]

Thomas, Hugh, La trata de esclavos, Barcelona, Planeta, 1998.

Tobón Restrepo, Alejandro; Londoño, María Eugenia; Zapata, Jesús, Entre sones y abozaos. Aproximación etnomusicológica a la obra de tres músicos de la tradición popular chocoana, Medellín, Universidad de Antioquía, 2005.

Urrea, Jesús, "Nuevas obras de Don Antonio Palomino", Boletín del Seminario de Estudios de Arte y Arqueología, núm. 49 (1983), págs. 493-496.

Vries, Elly de, “Arte e ciencia no Brasil holandés”, en Viajando con Eckout: roteiros para viajantes-professores, Recife, Instituto Ricardo Brennand, 2002, págs. 48-52.

Williams, Eric, Capitalismo y esclavitud, Madrid, historia 12, 2011.

Wolman, John, Consideraciones acerca de la posesión de esclavos. Alegato por los pobres, León, Universidad de León, 2000.

Zeuske, Michael, “' 'Sin otro apellido'. Nombres esclavos, marcadores raciales e identidades en la transformación de la Colonia a la República, Cuba 1879-1940", Tzintzun, Revista de Estudios Históricos, núm. 36 (2002), págs. 153-208. 